\title{
Differing indications
}

$\mathrm{E}$

thiopia has a unique calendar based on the Coptic calendar. You can go there and suddenly be 8 years younger. It is 2001 now in the country where both coffee and mankind are believed to have originated.

Yet, while Ethiopia is known for its diverse population and other relatively uncommon features such as having its own script for its official language, it is hardly alone in having suffered greatly from the AIDS epidemic.

An estimated 900000 Ethiopians had died from AIDS by 2003, a scant 17 years after the first report of HIV infection in Ethiopia, according to UNAIDS. In 2007 alone, 67000 people died of AIDS, making it the leading cause of mortality for the nation.

I was a general practitioner in Ethiopia prior to moving to Canada over 5 years ago. Providing care for people with HIV was the main part of my practice.

At the time, people considered being HIV-positive as a "death sentence," as they typically weren't offered life-prolonging measures. Few sought counselling or testing. The stigma associated with the infection often persuaded them to avoid medical intervention. Treatment, such as it existed with limited resources, was largely focused on containing opportunistic infections.

I returned to Ethiopia late last year, though, and saw light at the end of the tunnel. There are centres in the capital city, Addis Ababa, and also some regions of the country, that now provide HIV care that includes highlyactive antiretroviral treatment.

I felt hope seeing patients doing well on treatment, including a long-haul truck driver in his 50s. When he was diagnosed with HIV about 5 years ago, he decided to quit work and transfer his responsibilities to his children. But after starting treatment, he has been back on the road with his fleet for 2

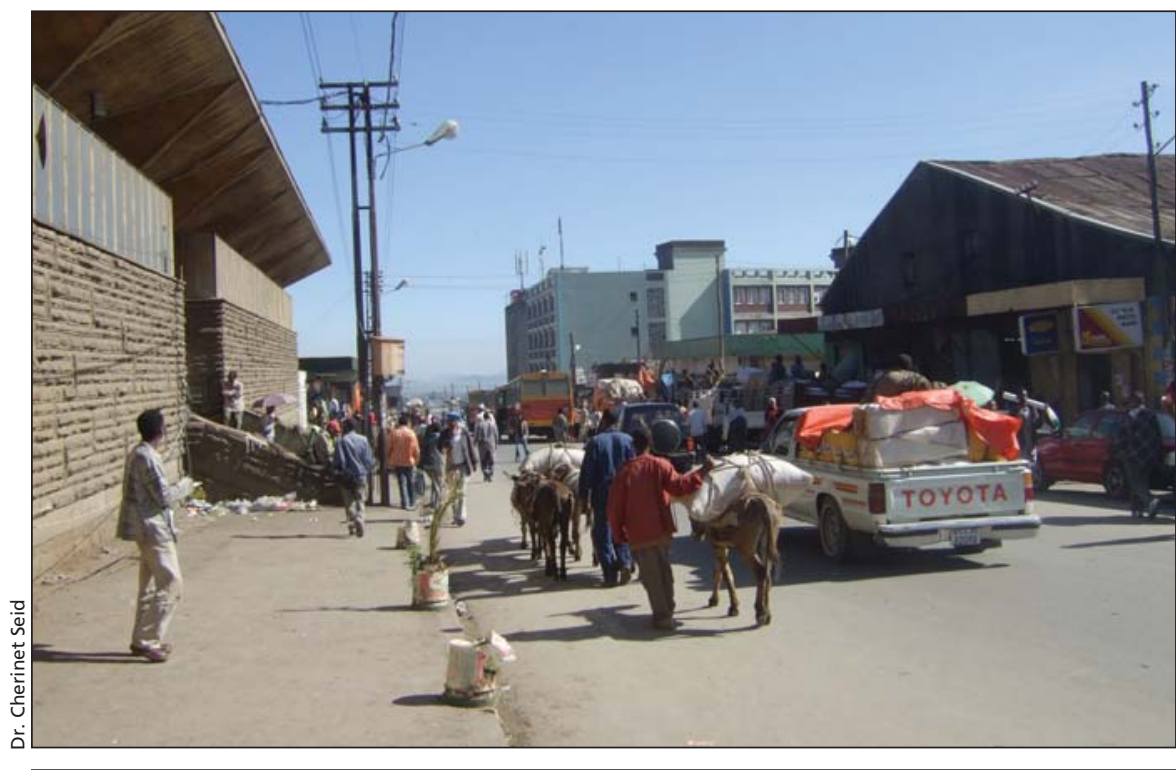

Addis Ababa boasts the biggest open market in Africa.

years - arranging his trips around medical appointments. He now seems as happy as he is grateful that the treatment enables him to again be a breadwinner for his family.

Administration of highly-active antiretroviral treatment was made possible through the collaboration of the Ethiopian government and various international bodies under the auspices of programs such as former United States President George Bush's Emergency Plan for AIDS Relief.

I think the Bush initiative is the most moral thing the Bush administration ever did and go down as his legacy in AfricanHIV history. The availability of highlyactive antiretroviral treatment includes both first line and second line treatment for both adults and children. All medications are provided free. People also get their $\mathrm{CD} 4$ count done for free, but have to pay for viral load determination on their own, although there is a centre that recently started providing this free as well. Resistance testing (genotype) is not performed, so clinicians have to depend on patient's CD4 count and clinical situation to change regimens.

The indication to start treatment differs from that used in the Western world: CD4 count of less than 200, and/or presence of AIDS-defining conditions. Pregnancy by itself is not an indication for treatment. Only prevention of perinatal transmission prevention is sought.

Still, HIV remains the primary public health problem in Ethiopia and much remains to be done to expand and improve the current level of care, as well as reduce the level of transmission. Cherinet Seid, MD, Ottawa, Ont.

DOI:10.1503/cmaj.109-3008

CMAJ invites contributions to "Dispatches from the medical front," in which physicians and other health care providers offer eyewitness glimpses of medical frontiers, whether defined by location or intervention. Submissions, which must run a maximum 700 words, should be forwarded to: wayne.kondro@cmaj.ca. 